ARTIGOS 



\section{Governando Camponeses: Colonato e Mobilidade no Império Romano Tardio ${ }^{1}$}

Uiran Gebara da Silva*

Resumo: As "leis do colonato" foram tradicionalmente vistas como um conjunto coerente de determinações jurídicas com o objetivo de prender os camponeses na terra entre os séculos III e V d.C. Estas leis desempenharam um papel central na construção historiográfica que, durante o século XX, propunha um rebaixamento do estatuto e das condições sociais dos camponeses do Império Romano tardio. Este artigo revisita os problemas ligados ao uso dessa documentação legal à luz da contestação da visão historiográfica anterior sobre as leis do colonato, iniciada na década de 1980 . Tal revisitação tem como perspectiva avaliar em que medida o estado atual desse debate pode interferir na investigação e nas representações dos trabalhadores rurais tardo-romanos, suas comunidades e as diversas configurações de poder (local ou imperial) com as quais eles tinham de lidar.

Palavras-chave: Colonato. Campesinato. Império Romano Tardio.

O estudo do passado romano, em particular o estudo das regiões rurais do Império Romano, passou boa parte do século XX sendo permeado por muitas certezas. Dentre essas certezas, deve-se dar um destaque especial à visão de que houvera entre os séculos III e V d.C. um processo linear de subordinação dos trabalhadores rurais livres no Império Romano a vínculos sociais e legais de dependência. É, contudo, importante reconhecer que mudanças

"Doutor em História Social pela Universidade de São Paulo - USP. Pesquisador em pós-doutoramento na mesma instituição. E-mail: uirangs@usp.br

Anos 90, Porto Alegre, v. 24, n. 46, p. 185-210, dez. 2017 
vêm ocorrendo nas últimas décadas e que algumas certezas e alguns consensos, muito sólidos ao longo do século passado, têm progressivamente sido postos em questão. A investigação a respeito da vida e do cotidiano dos trabalhadores rurais tardo-romanos passou por mudanças importantes, tanto do ponto de vista dos métodos e pressupostos teóricos de análise da documentação escrita, quanto do ponto de vista do impacto da arqueologia rural, que deixou de servir de ilustração daquilo que se inferia dos textos antigos e passou a oferecer questionamentos e perspectivas complementares ao que se encontra na literatura antiga.

As "leis do colonato" foram durante muito tempo vistas como um conjunto coerente de determinações jurídicas cujo objetivo seria prender os camponeses na terra em um período de crise social do Império. ${ }^{2}$ Essas leis desempenharam um papel central na construção historiográfica, enraizada ao longo de todo o século XX, que propôs a existência de um rebaixamento das condições sociais dos camponeses do Império Romano tardio (ANDERSON, 2000; DE COULANGES, 1894; FINLEY, 1991; JONES, 1958; STE. CROIX, 1998; C. R. WHITTAKER, 1993). Contudo, essa construção historiográfica não é mais tão aceita hoje em dia quanto era há alguns anos.

Tendo como ponto de partida essa contestação da visão historiográfica anterior, o propósito deste artigo é levantar algumas questões sobre a noção de liberdade que pode ser atribuída à documentação legal relativa às leis do colonato, refletir a respeito das configurações de poder estatal que se encontram expressas na legislação e examinar suas implicações para a o desenvolvimento de nossa compreensão das comunidades locais e das ações dos trabalhadores rurais entre os séculos III e V. Para tal tarefa, em realidade, concentro a análise aqui realizada em uma lei apenas: a Novella 31 de Valentiniano III. ${ }^{3}$

Primeiramente, acredito que seja importante estabelecer alguns parâmetros conceituais. Estou usando o conceito de Estado para me referir ao sistema político do Império Romano pois acredito no valor heurístico dele. Pensar esse sistema por meio desse conceito permite-me refletir sobre a autonomia relativa que o governo romano (e suas múltiplas instituições) expressa em relação à sociedade e às diferentes classes sociais. ${ }^{4} \mathrm{O}$ governo imperial tem um papel administrativo que se expressa na regulamentação da produção 
e distribuição das riquezas, no regramento legal das relações de dominação e dos conflitos sociais das províncias, das cidades e do campo e eu penso que essas ações não podem ser entendias apenas com recurso ao exame das relações pessoais diretas. Há um nível de compreensão desse governo que só pode ser entendido se observarmos as contradições internas das classes dominantes, como grupos em disputa por essa instituição de dominação, e as conexões desse governo com as classes subalternas que mantêm e reelaboram as relações de dominação. ${ }^{5}$

Num registro similar, a densidade conceitual da palavra "campesinato" tem desencorajado o seu uso por historiadores da Antiguidade nos últimos tempos, e um desafio direto ao seu emprego foi feito por Horden e Purcell (2000). Contudo, é esta categoria que emprego para operar teoricamente a compreensão dos trabalhadores rurais livres, os rustici, incolae, agricolae e coloni da documentação sobre as regiões rurais do Império tardio. Assim o faço porque a categoria "campesinato", ao pressupor a família camponesa como célula fundamental de organização social, permite iluminar e problematizar as conexões entre as mutáveis condições de trabalho (entre o arrendamento e a pequena propriedade), as variações de estatuto social (do emprego assessório e sazonal ao moderadamente rico líder local) e a organização política das comunidades locais desses atores sociais. ${ }^{6}$

As conexões que mencionei são geralmente ignoradas na visão das regiões rurais que predominou ao longo do século XX e uma das principais razões para isso é um quadro de interpretação que observa todo o Mediterrâneo entre os séculos III e VII em termos do crescimento linear das relações de dependência pessoal.

Pode-se dizer que esse enquadramento teórico se apoia em três pilares: 1) a ideia de uma crise econômica, social e política de longa duração; 2) a visão quase a-histórica de patronato das classes dominantes sobre as classes subalternas; e 3) a criação de uma ordem social de camponeses presos à terra, prenunciadora da servidão feudal: o colonato. Não pretendo me aprofundar no que diz respeito aos dois primeiros pilares desse enquadramento, muito embora sejam necessárias algumas considerações. Em primeiro lugar, ambos são partes integrantes do duradouro paradigma de "Declínio e Queda 
do Império Romano" e nem o grande paradigma, nem as crises econômica, social e política, nem o patronato ubíquo podem ser dados como pressupostos indiscutíveis para os historiadores que hoje investigam a Antiguidade Tardia.

Isso que estou chamando de a ideia de "crise" de longa duração era um conjunto de modelos explicativos, nem sempre pensados explicitamente como modelos, que viam um prolongado e generalizado processo de crise social, política e econômica em todas as regiões do Império Romano tardio. As causas e razões dessas crises foram um dos grandes debates historiográficos do século XX, que gerou muitas respostas, não raro contraditórias. ${ }^{7}$ Esse paradigma foi consensual até os anos 1980, momento a partir do qual o acúmulo de pesquisas pontuais, que partem tanto do refinamento da compreensão das estruturas literárias das fontes textuais, quanto da profusão de estudos arqueológicos, propiciou a problematização, o questionamento e a desconstrução desse paradigma. O desenvolvimento a partir dos anos 1970 da noção de Antiguidade Tardia contribuiu para modificar radicalmente esse cenário anterior. ${ }^{8}$ Assim, até o começo do século XXI o paradigma interpretativo dominante sobre o Império Romano tardio não mais se baseava nos conceitos de crise, decadência ou em queda, substituindo-os por uma visão de transformações lentas e enfatizando as continuidades. ${ }^{9}$ Nesse novo contexto dos estudos, para alguns deixou de ser válido interpretar o século III d.C. como um período de crise. Os séculos III, IV e V passaram a ser vistos como uma etapa de reajuste do crescimento econômico excepcional romano nos séculos I a.C. a II d.C., acompanhado de novas modalidades de relação das elites locais e regionais com a corte imperial, com a ascensão de novos centros imperiais e com a cristianização dessas elites (BROWN, 2003; MATTHEWS, 1990). No início do século XXI, alguns historiadores voltaram a trabalhar com a perspectiva de crise (política, social e/ou econômica) apenas para o século V (com a crise do III sendo circunscrita a uma crise militar ou política), mas mesmo para esses autores tal crise é de curta duração, com súbito impacto e diretamente associada à presença dos bárbaros (GIARDINA, 2007; HEATHER, 2006; WARD-PERKINS, 2005). 
Já a visão quase a-histórica de patronato das classes dominantes sobre as classes subalternas depende de uma tendência da historiografia em enfatizar a versatilidade e a multiplicidade de estratégias que as aristocracias romanas, pré-romanas, e pós-romanas seriam capazes de empregar para manter a dominação sobre os habitantes das zonas rurais. No que diz respeito ao Império tardio, em via de regra, essa tendência se apoia na observação do desenvolvimento de formas de dominação pessoal dos camponeses pelas aristocracias nas províncias e depois nos novos reinos bárbaros, com a queda do Império nas regiões ocidentais do Mediterrâneo. ${ }^{10}$ Essa perspectiva se apoia na projeção das relações de clientelismo urbano de Roma e na generalização de certa interpretação dos textos de Salviano de Marselha e das Orações de Libânio para todo o contexto rural do Mediterrâneo, assim como no uso indiscriminado de teorias de patronato rural como chave explicativa de todos os fenômenos sociais. ${ }^{11}$ Contudo é importante ter em mente que os modelos de organização social rural presentes na historiografia se transformaram profundamente nas últimas décadas, com a historiografia sobre a organização das relações de trabalho e de poder no campo do Império tardio hoje bem menos marcada por consensos do que anteriormente. O resultado mais claro, e talvez provisório, dessas mudanças na historiografia e na arqueologia é que as visões mais homogeneizadoras das interpretações anteriores (weberianas, marxistas, braudelianas, todas, sem exceção) foram substituídas por uma perspectiva bem diversificada das condições sociais das comunidades rurais tardo-romanas. Essas mudanças derivaram das transformações nas abordagens metodológicas na leitura da documentação, dos modelos conceituais empregados para explicar as relações sociais nas zonas rurais do Império e, por fim, do profundo impacto do avanço da arqueologia nesse campo de estudos, e resultaram na revisão da excessiva centralidade dada pela historiografia anterior às ideias de villa, colonato e sociedade escravista (BOWDEN; LAVAN; MACHADO, 2004; DYSON, 2003; WICKHAM, 2005).

Muito embora a discussão sobre patronato rural também se baseie largamente em discussões sobre o papel do Estado na regulação das relações entre camponeses e figuras poderosas no campo, a 
criação do colonato é, dentre os três pilares, o que mais diretamente toca o tema que propus acima, a saber, a relação das comunidades rurais com o poder estatal. Por causa disso me concentrarei nele. Além disso, pôr em questão a hipótese de o colonato ser uma ordem social de homens "meio livres" permite problematizar que concepção (ou concepções) de liberdade o texto legal tardo-romano opera (que me parece ser diferente daquela com a qual os historiadores modernos trabalham).

Como mencionado acima, a perspectiva historiográfica sobre o colonato tardo-romano tomava sua base documental a partir da existência de inúmeras leis nos códigos de Teodosiano e Justiniano e se estabeleceu como consensual ao longo do século XX. Ainda sob o paradigma de "Declínio e Queda" do Império, propunha que, como resposta à decadência da escravidão rural, o Império tardio teria legalmente vinculado todo o campesinato à terra, aprofundando a dominação aristocrática no campo e rebaixando as condições de vida dos camponeses a uma forma de semiescravidão. ${ }^{12}$ Até o início do século XX, porém, essa perspectiva era parte de um enorme debate e fora anteriormente criticada por alguns historiadores que acreditavam que se poderia antecipar essa prática para o período inicial do Império, ou que ela já existira antes apenas nas províncias (na Gália, ou na África, ou nas do Oriente), que tinha sido parte de um experimento de assentamento de povos bárbaros, ou que a legislação apresentava apenas a formalização legal e/ou generalização de relações já estabelecidas no costume, como as relações de patronato. ${ }^{13}$ Essa última posição foi mais enfaticamente defendida por Fustel de Coulanges e permaneceu viva ao longo do século XX (DE COULANGES, 1894), embora subordinada à leitura que punha mais acento nas reformas legais como forma de manter o suprimento de mão de obra rural. Mas mesmo nesse período anterior ao consenso, o debate girava em torno das origens ou da genealogia do colonato, e a sua existência como uma ordem ou estatuto pessoal, que colocava os camponeses numa condição entre os livres e os escravos, nunca foi posta em questão.

No início dos anos 1980, essa perspectiva passou por uma severa releitura iniciada pela intervenção de Jean Michel-Carrié no debate. No contexto de um debate sobre o livro Escravidão Antiga 
e Ideologia Moderna publicado pela revista italiana Opus, Carrié tomou como ponto de partida as críticas de Finley à ideia de crise da escravidão no Império tardio (FINLEY, 1991) ${ }^{14}$ e questionou Finley por não desenvolver radicalmente o que isso significava em termos das relações de trabalho rurais no Império tardio. Isto é, que não teria havido necessidade econômica e social de se vincular o campesinato à terra, o que tornava pouco verossímeis as interpretações das leis sobre colonato como respondendo a necessidades sociais (CARRIÉ, 1982a). Em seguida, Carrié sugeriu que a construção do colonato na historiografia se constituía em uma projeção das relações de servidão feudais para o período da Antiguidade Tardia, cujo principal elaborador moderno teria sido Fustel de Coulanges, daí a extensa desconstrução e apresentação dos pressupostos ideológicos da obra de De Coulanges (CARRIÉ, 1982b). Posteriormente, Carrié argumentou que as leis não são coerentes entre si e não tratam de situações homogêneas no que diz respeito ao status ou condição social dos colonos, e que apenas a preocupação com o controle da cobrança de impostos e com a punição para aqueles que os sonegassem atua nelas como elemento comum (CARRIÉ, 1983). Os argumentos de Carrié puseram em questão um modelo que estivera cristalizado por muito tempo e o debate, que se desenvolve há 30 anos, em meio a intervenções ponderadas (GOFFART, 2008; LO CASCIO, 1997; MARCONE, 1988; MARTINO, 1993; SCHEIDEL, 2000; SIRKS, 2001; WARD-PERKINS, 2000; C. R. WHITTAKER, 1993) e outras nem tanto (MARCONE, 1985; MIRKOVI, 1997; ROSAFIO, 2002), não voltou a nenhum patamar consensual até hoje, ao contrário do que considera Cam Grey (2007).

Talvez por causa disso, a problemática do colonato ainda é inescapável quando se olha para as comunidades rurais da Antiguidade Tardia. A contribuição de Jean-Michel Carrié, que causou o reacender do debate sobre o colonato, permite um outro olhar sobre a legislação e as configurações do poder estatal. E, nesse novo contexto, a busca daquelas conexões entre governo romano e comunidades rurais que mencionei anteriormente encontra um universo de representações bem mais interessante nessas comunidades rurais do que aqueles que eram esboçados na teoria sobre o colonato anteriormente predominante. 
As ambiguidades das leituras modernas da legislação, principalmente no que diz respeito ao conceito de libertas, tem profundas implicações para a compreensão das práticas de governo imperial sobre os camponeses. Para o consenso historiográfico anterior, essa compreensão dependia em larga medida da pressuposição daquele modelo de crescimento linear da dependência pessoal e da leitura de uma noção de liberdade concebida em termos modernos (isto é, como uma condição homogênea e absoluta) no texto legal romano.

O trecho abaixo foi retirado da Novella 31 de Valentiniano III porque essa passagem em particular oferece uma dessas situações nas quais diferentes enquadramentos teóricos conduzem a diferentes compreensões (e traduções) do sentido do texto original e me parece que é bem representativo das divergências que ocorrem na historiografia sobre o colonato. Essa lei é de 451 e foi endereçada a Firminus, o Prefeito do Pretório - provavelmente da Itália e da África (JONES; MARTINDALE, 1980, p. 471). Ela trata basicamente das ações necessárias para controlar colonos (coloni) errantes, assim como do trânsito de outras categorias de pessoas vindas de outras províncias. A lei também busca estabelecer regras sobre casamento de forasteiros com colonas (colonae) e sobre as obrigações dos filhos de colonos com mulheres livres para com o sistema fiscal.

O que se segue abaixo é a passagem inicial da lei que lida com a correção de desvios praticados por colonos que encontraram margens de manobra em uma lei anterior regulamentando as condições de colono e de inquilino.

"Enquanto devam ser observadas pura e fielmente as coisas que são cravadas nas leis, reconhecemos que a lei apresentada há pouco tempo sobre coloni originarii tem sofrido trapaças [feitas] pela mente maligna de alguns homens. Pois enquanto aquele, de quem o delinquente se afastou, é rechaçado pela objeção dos trinta anos, [o colono] consome o tempo designado indo a uns e outros. Assim acontece que, embora [o colono] expire para aquele de quem fugiu, também não pode ser adquirido por este, a quem veio; por meio da mudança de habitações, cessa de existir uma liberdade, porque diz-se que com ela nasceu, defendendo, com a reincidência da fuga, uma que não teve ao nascer. Nunca e para ninguém houve, a não ser para um colono fugitivo, um prêmio por seu delito: a 
razão pela qual começa a se tornar melhor é a mesma pela qual é merecedor de punição."15

O primeiro elemento para o qual eu gostaria de chamar a atenção nessa passagem é o uso do termo colonus originarius. Para os historiadores defensores da ideia de que o colonato é uma ordem inferior, essa expressão pertenceria a um campo de expressões correlatas presentes na legislação (inquilini, iuri alieni, censibus adscripti, adscripti, enapographoi), todas denotando a vinculação pessoal do colono a um dominus (se do colono ou da terra é algo que permaneceu sempre em discussão) e nas suas versões mais fortes, propondo um processo de generalização dessa condição para todo o campesinato tardo-romano. ${ }^{16}$ A homogeneidade desse campo nunca foi um dado certo e resultou em numerosos debates dentro da visão consensual anterior.

Igualmente, esse debate não diz respeito apenas às interpretações ou categorizações explícitas do colonato feitas por historiadores. Ele está presente de uma forma ainda mais insidiosa, pois atua no plano da tradução da documentação textual para línguas modernas, já que, dependendo da corrente interpretativa preferida pelo tradutor, o texto da lei pode mudar de sentido. A tradução para o português que apresentei acima não supõe que o colonato fosse uma ordem inferior estabelecida por nascimento. Porém, esse é um pressuposto fundamental da tradução proposta por Clyde Pharr em sua edição inglesa do Código Teodosiano, a versão traduzida mais encontrada em estudos sobre o colonato no mundo anglo-saxão (PHARR, 2001, p. 540-541).

"Although the provisions which have been made in the laws must be unconditionally and faithfully observed, we have learned that the law which was formerly issued with reference to coloni by birth status is suffering perversion by the malignant minds of certain persons. For since a person from whom an obligated colonus departs is defeated by the prescription of thirty years, the designated period of time is consumed by the colonus who goes from one person to another. Thus it happens that although the colonus is lost to the person from whom he flees, yet he cannot be acquired by the person to whom he comes. By constant change of his abode he ceases to be what17 he was born, and he vindicates for himself, by 
the constant repetition of his flight the freedom which he did not have by birth status. To no person ever, except a fugitive colonus has his misdeed been a reward; he begins to acquire better status for the very reason for which he deserves punishment". ${ }^{18}$

No contexto dessa interpretação, originarius e algumas palavras cognatas (origo, orignaris, originalis) enfatizariam a condição de nascença em uma ordem inferior. E nesse contexto, o resto da lei estaria discutindo qual o estatuto legal, isto é, a qual ordem pertenceriam os filhos dos colonos.

Há, no entanto, outra leitura possível que entende o termo originarius e palavras correlatas, principalmente origo, como uma indicação do local de referência para a cobrança de tributos (annona e tributa) ou prestação de serviços públicos (munera). Essa leitura, que apareceu primeiro no artigo de Charles Saumagne (1937) sobre o colonato, está presente e problematizada como a origem fiscal do colonato nos estudos de Jones $(1958,1974,1992)$ - que ainda assim via o colonato como se tornando uma condição dependente -, no estudo de Walter Goffart sobre a capitatio (1974) e é a base para a perspectiva de Carrié $(1983,1997)$, assim como para a interpretação de Cam Grey $(2007,2011)$. Nesse sentido, a vinculação dos camponeses a uma origo, isto é, a uma residência fiscal, não seria uma exceção, mas a regra prescrita pelo governo imperial para a maior parte da sua população que era responsável por pagar impostos ou tributos, ou por prestar alguma forma de serviço público. Um uso de origo nestes termos pode ser encontrado se referindo a curiais, por exemplo (Cod. Th. 12.1.102), mas há muitos outros casos como os de fabricantes de navios, padeiros e de tinturas imperiais. ${ }^{19}$

Ao se retornar à leitura de Pharr, fica claro que nela o colono é entendido literalmente como um homem não livre: ele busca uma liberdade que não tem. Essa leitura é estranha, pois não condiz com a imensa maioria das leis do Código Teodosiano (e no Código Justiniano) que mencionam o colonato. Pois, mesmo aquelas leis que enfatizam indubitavelmente a vinculação do colono com uma propriedade territorial costumam deixar o leitor moderno perplexo com a afirmação da condição livre do tal colono (ingenuus). ${ }^{20} \mathrm{Um}$ outro elemento importante dessa leitura é que a liberdade nesse caso é entendida como um conceito absoluto e pleno. 
A primeira tradução apresentada aqui parte de uma outra compreensão do texto latino que pode ser qualificada a partir de duas dimensões. Em primeiro lugar, ela dialoga com a perplexidade no leitor moderno causada por outras leis sobre colonos, isto é, ela é mais coerente com o corpo de leis que tratam do colonato. Adicionalmente, essa perplexidade é um efeito criado pelo significado diferente que a ideia de libertas apresenta no contexto desse código. Em lugar de entender a libertas presente nesse trecho como uma condição absoluta e abstrata dos cidadãos livres do império, ${ }^{21}$ busco aqui pensá-la como parte daquele espectro de estatutos proposto por Moses Finley, caracterizado por condições substantivas e definidas por diferentes tipos de direitos ou liberdades, que vão do escravo ao mais alto estatuto entre os livres (1999, p. 35-61). Autores que buscam entender a libertas como absoluta perdem de vista o quão moderna e recente é a ideia absoluta de liberdade e o quanto o Império Romano tardio estruturou a sua cidadania universal em torno de ordenamentos sociais hierarquizados e constituídos de diferentes direitos a cada um dos níveis. Mesmo Finley, ao construir o espectro de estatutos pessoais, elegeu como pressuposto fundamental a dependência pessoal que distingue entre os vários estatutos e dessa forma a condição de livre parece ser mais homogênea e abstrata do que realmente era. Há muitos estatutos e muitas liberdades, e libertas não deve ser entendida como uma condição abstrata, mas como várias condições substantivas.

Decerto, a divisão formal (e prática) fundamental era entre livre e escravo, com o escravo sendo considerado um não cidadão e, por isso, sem direitos. ${ }^{22}$ Contudo, ao contrário do que é geralmente assumido, a relação entre cidadania universalizada ${ }^{23}$ e os direitos discricionários não significou necessariamente um rebaixamento da condição estatutária dos cidadãos que não eram parte da elite, os humiliores, nas várias cidades do Império tardio. É possível demonstrar e argumentar que isso abriu aos cidadãos livres de baixo estatuto a possibilidade de recorrer a uma instância legal superior à lei ou ao costume locais. Uma instância à qual muitos não tinham acesso antes, mas que passou a existir, com as cidades do Império que não eram anteriormente consideradas municipia passando a ostentar tal estatuto. Assim a lei civil passou a englobar, complementar e, em 
certos casos, subordinar as leis locais, regulamentando as formas pelas quais os governadores provinciais (e seus assessores) poderiam interceder legalmente em litígios locais (HARRIES, 1999; HONORÉ, 2004). E nesse sentido, porque eram considerados cidadãos, mesmo quando eram parte dos humiliores, tinham inclusive a possibilidade formal de pedir proteção jurídica. Ainda que tal pedido fosse mediado por pagamentos pelos serviços, pode-se argumentar que isso era mais acessível do que as vias unicamente clientelísticas do período inicial do Império, como faz Christopher Kelly (2006). $\mathrm{O}$ pertencimento à categoria dos livres não garantia a todos uma condição homogênea, pois estes eram divididos em vários níveis ou ordens, dentre as quais humiliores e honestiores eram a primeira grande divisão, que possuíam conjuntos de direitos diferentes para cada uma dessas ordens. ${ }^{24}$ A eficácia ou não desses direitos, isto é, a possibilidade efetiva de um humilior conseguir fazer o Estado atuar em seu favor é uma dimensão prática importante, que, contudo, não pode ser definida a priori pela condescendência da posteridade, mas pelo estudo e pela análise da documentação. Assim, mesmo que se presuma que sejam casos isolados, as inscrições africanas (SK, 182 CE; CIL VIII 10570, 14454), da época de Cômodo, erigidas por colonos de terras imperiais agradecendo ao Imperador por ter intervindo contra intermediários (conductores e procuratores), servem de alerta de que esses direitos apresentavam algum grau de eficácia (KEHOE, 2007, p. 73-74).

A partir dessa perspectiva, o sentido da segunda passagem em destaque é de que o colono ingenuus e humilior, ao fugir das suas obrigações, trocava uma liberdade (a de nascença, oposta à escravidão e condizente com um conjunto positivo de direitos) por outra (a de movimento, que não teria enquanto trabalhador rural vinculado a uma origo), e a liberdade de movimento do colono é justamente o objeto de regulação dessa passagem da Novella 31 de Valentiniano III. A necessidade dessa regulação, por sua vez, permite colocar em questão a força da dependência pessoal.

O governante afirma que uma lei anterior (Cod. Th. 5.18 de 419) está sendo burlada. Essa lei anterior firmava um período de trinta anos como limite para qualquer processo legal que tentasse reaver para uma propriedade original um colono que tivesse fugido 
de sua origo. Esses trinta anos, por sua vez, não são arbitrários, eles derivam de uma lei ainda anterior que impunha tal período como limite para quaisquer processos jurídicos relativos a dívidas privadas ou públicas ou à cobrança de obrigações não cumpridas (Cod. Th. 4.14.1 de 424; Cod. Th. 12.19 de 400). De acordo com o que é descrito na Novella 31, alguns dos colonos que deixam a propriedade que têm como origo, e por meio da qual deveriam pagar os impostos, aparentemente estavam conseguindo driblar com sucesso a lei dos trinta anos, movimentando-se entre diversas propriedades rurais, de forma que não completassem os trinta anos em nenhum lugar por onde passassem e, assim, o proprietário de sua origo inicial tivesse enormes dificuldades em achá-lo ou em reavê-lo mesmo tendo conseguido encontrá-lo. A resposta do legislador a isso é propor um conjunto de regras que permitisse aos proprietários aos quais o colono se associou ao longo do tempo estabelecerem, em caso de processo legal, qual propriedade teria prioridade sobre o colono e, principalmente, quem deveria ser multado e pagar os impostos indevidamente cobrados do proprietário sem trabalhador. Temos aqui, de fato, um poder estatal reforçando o controle dos proprietários de terras sobre trabalhadores rurais a eles vinculados por um contrato duradouro de arrendamento. Contudo, os pressupostos e as implicações sociais dessa legislação parecem apontar numa direção diferente do que afirma a historiografia anterior.

A historiografia sobre os trabalhadores rurais do Império tardio, principalmente essa que vê aí a subordinação deles a uma condição semilivre, sempre lê essas leis a contrapelo, mas a contrapelo patronal. A lei é sempre entendida do ponto de vista do que os poderosos podem fazer com ela, sejam os poderosos vistos em sua dimensão econômica, como a classe dos proprietários, seja em sua dimensão política, como representantes do Estado. Dado que o historiador da Antiguidade está buscando entender e reconstruir o funcionamento de uma sociedade de classes baseada no trabalho agrário, entender como a lei e as práticas de governo respondem aos interesses da classe proprietária é parte do seu trabalho. No entanto, o problema é que na maior parte das vezes a análise dessas relações para aí, no emprego da lei pelos poderosos. Assim, mesmo quando se demonstra, como Carrié o fez, que a legislação sobre o 
colonato tinha fins meramente fiscais, ainda é possível entender essas leis em termos de favorecimento dos poderosos. Contudo, há mais dimensões sociais que essa interpretação patronal ignora. É necessário operar com a perspectiva a contrapelo das classes subalternas (BENJAMIN, 1996) e também refletir sobre o que os coloni fazem da lei (GREY, 2011; HARRIES, 1999, p. 188-190).

Assim, o primeiro passo para poder imaginar o que os colonos fazem da lei é apresentar algumas questões suscitadas pela leitura a contrapelo da Novella 31 de Valentiniano III. Em primeiro lugar, deve-se questionar a ideia de que há grande valor na hipótese de controle baseado no poder pessoal direto do proprietário sobre os colonos, pois esse controle direto é permeável o suficiente para que o colono burle sistematicamente a sua vinculação à terra onde deveria estar legalmente. Parece-me que o poder pessoal do proprietário não pode ser definido de forma desarticulada das configurações do poder estatal expressas nessas leis e que, ainda assim, o que aparece aqui são expressões de negociação e conflito constante entre os camponeses, os proprietários que os recebem, os dos quais fogem e os representantes do governo romano. Talvez o modelo de relações sociais rurais a ser aplicado aqui não seja o das relações de patronato em processo de fortalecimento, mas, ao contrário, aquele que remete às disputas cotidianas entre grandes proprietários e trabalhadores rurais (SCOTT, 1985). Pode-se tentar responder isso apenas olhando para o contexto imediato das relações entre os proprietários e os trabalhadores rurais, mas talvez seja o caso de ampliar o foco e pensar como essas disputas cotidianas se articulam a algumas indagações mais gerais ou abstratas sobre a relação entre poder político e relações sociais.

Assim, as disputas e negociações que estão pressupostas e que dão sentido a essas leis só aparecem na documentação legal porque tocaram em algum momento num outro nível de conflitos sociais: aqueles relacionados aos interesses das facções de classes dominantes e sua relação com os grupos políticos que atuam nas instituições do governo imperial. A consolidação e manutenção dessa estrutura discricionária de direitos e liberdades na legislação tardo-romana responde a necessidades desse sistema político, dentre 
os quais, primeiramente, a manutenção da tributação, mas também à consolidação e manutenção da ordem social. Nesse sentido, a tradição historiográfica que vê um aumento do poder pessoal dos grandes proprietários, ao enfatizar o caráter centrífugo da atuação destes, enxerga o processo de acumulação de riquezas e exploração do camponês como algo que pode ser facilmente desvinculado das relações de poder condensadas no sistema político imperial, isto é, no Estado romano. O outro lado da moeda são as interpretações tradicionais da ação desse sistema político como algo autônomo e puramente interessado na tributação, para as quais o controle dos camponeses e a regulação das relações de trabalho é um meio para um fim: a manutenção da ordem romana, principalmente no que diz respeito ao conflito com bárbaros ou com o império vizinho. Ambas as posições tendem a perder de vista a imbricação entre as elites rurais e o sistema político, e acabam por não problematizar adequadamente o fenômeno que se observa na regulamentação que as leis sobre o colonato e sobre o patrocínio representam do ponto de vista social: os limites impostos pelo Estado romano ao processo de acumulação de riqueza pelas elites rurais são parte do processo de reprodução desse sistema político e dessas classes dominantes que, separadas dele, assumiriam (e assumiram) um caráter bem diferente (WICKHAM, 2005, p. 303-379).

Por fim, há questões ligadas a outras dimensões da vida e ao trabalho rural que não são frequentemente endereçadas a essa documentação. Muitas das análises da condição do camponês tardo-romano e do colonato como instituição representam os colonos como indivíduos desenraizados, desapegados das comunidades rurais onde nascem, vivem e trabalham. Acredito, porém, que o passo analítico que deva ser dado agora é entender os colonos como parte de comunidades rurais, mesmo que transitoriamente. No que diz respeito à Novella 31, isso suscita algumas indagações a respeito dessas comunidades rurais pelas quais os colonos passam e que permitem a perambulação descrita na lei. Pode-se perguntar como se dá o reconhecimento desses colonos peregrinos pelas comunidades de onde saem e aonde chegam, ou como o processo legal que busca recuperar o colono e sua família para uma origo anterior se articula 
com essas comunidades, já que o reconhecimento dos colonos, em algum nível, se dá por meio das comunidades rurais. Ou, ainda, como as regulamentações que orientam o casamento entre grupos de diferentes condições sociais contribui para entender a interação entre os diferentes estamentos e a articulação dos conjuntos diversos de direitos associados a honestiores e humiliores. Isso se articula com a representação homogênea que durante muito tempo se fez das comunidades rurais tardo-romanas. Uma das marcas da nova historiografia é acentuar o grau de heterogeneidade na composição das comunidades rurais e a diversidade de relações de trabalho que se pode encontrar nelas. Isso se coloca em frontal oposição à historiografia tradicional sobre o colonato que tendeu a ver coloni originarii em toda a parte por causa da quantidade de páginas dedicadas a eles nas leis. Essa homogeneidade pode ter sido uma distorção na nossa visão moderna causada pela expressão legal de um fenômeno social que não é expressão necessária da sua generalização social, mas da sua complexidade em termos legais. $\mathrm{O}$ conjunto da documentação parece indicar que essas comunidades eram compostas por diversos tipos de trabalhadores rurais e camponeses com diversos tipos de relações de contrato ou propriedade da terra: pequenos proprietários, arrendatários de contrato duradouro ou curto, trabalhadores sazonais que transitam entre diferentes comunidades e escravos que ainda seriam parte do cenário rural por um bom tempo.

Essa dimensão social ou comunitária não é diretamente mencionada na lei (embora esteja lá pressuposta) e fica obscurecida pela tríade império-proprietário-colono da historiografia do século XX. É tendo em mente essa dimensão comunitária rural e o papel que ela tem como suporte da prática social e da agência dos camponeses tardo-romanos que o estudo sobre camponeses tardo-romanos pode ser desenvolvido. Durante muito tempo, o paradigma de um Império em decadência (econômica, social, moral) tornava essas questões e as respostas que elas poderiam trazer menos atraentes. A historiografia e a arqueologia sobre o Império Romano tardio têm apresentado atualmente um cenário bem diferente do que acontecia nas regiões rurais do Império entre os séculos III e V e essas mudanças no nosso conhecimento tornam as questões acima cada dia mais atraentes e justificadas. 


\section{RULING PEASANTS: COLONATE AND MOBILITY IN THE LATER ROMAN EMPIRE}

Abstract: The "colonate laws" were traditionally seen as a coherent set of judicial determinations aimed at binding peasants in the land between the 3rd and 5th centuries A.D. Those laws fulfilled a central role in the historiographical construct that, throughout the whole 20th century, stated a downgrading of the social status and a decrease in comfort of Later Roman peasants. This article readdresses the problems that surround the use of legal documentation, following the debates initiated in the 1980s that deconstructed the previous historiographical perspective on the colonate laws. Such readdress has as its goal to evaluate how much the actual state of the question still can affect the investigation and the historical representations of the Late Roman rural workers, their communities, and the several configurations of power (local or imperial) with which they had to deal in their daily lives.

Keywords: Colonate. Peasantry. Later Roman Empire.

\section{Notas}

${ }^{1}$ Este texto é uma versão desenvolvida a partir da apresentação realizada no IV Colóquio Internacional e VI Colóquio Nacional do LEIR (Laboratório de Estudos sobre o Império Romano) - Franca - Imperadores e Governantes da Antiguidade Clássica e Tardia: Estratégicas Bélicas, Políticas e Culturais. Agradeço pelos apontamentos realizados durante a discussão do painel por Jean-Michel Carrié, Margarida Maria de Carvalho, Pablo C. Díaz e Fábio Duarte Joly, assim como pelos questionamentos e contribuições de Camila Aline Zanon, Fábio Augusto Morales e Norberto Luiz Guarinello que travaram contato com a versão estendida do manuscrito. É imperioso afirmar que, embora quaisquer méritos do texto devam ser compartilhados, as deficiências devem ser imputadas unicamente ao autor.

${ }^{2}$ A historiografia sobre o colonato é extensa. Um bom ponto para começar são os estudos de Clausing (1925), Marcone (1988) e Giliberti (1999).

${ }^{3}$ Consultei aqui a edição do Código de Teodósio editada por Mommsen e Meyer, que também inclui as Constitutiones Sirmondianae e as Novellae e a tradução de Clyde Pharr, feita a partir dessa mesma edição. As novellae são editos ou decretos imperiais que foram promulgados depois da publicação do Código Theodosiano (o mesmo ocorreu após a publicação do Corpus Juris Civilis de Justiniano). A novela 31 de Valentiniano III é uma das leis promulgadas por este imperador em 451 cujo objetivo era lidar com colonos (coloni) errantes e

Anos 90, Porto Alegre, v. 24, n. 46, p. 185-210, dez. 2017 
legislar sobre o casamento de forasteiros com colonas (colonae) e colonos com mulheres livres. (MOMMSEN; MEYER, 1954; PHARR, 2001, p. 540-541). Sobre a criação e publicação do código, cf. Matthews (2000), sobre a edição de Mommsen, cf. Croke (1993) e sobre as novellae, cf. Harries (1999, p. 19-26, p. 61). ${ }^{4}$ Para uma discussão mais geral sobre o uso de conceitos modernos e das ciências sociais na Antiguidade, cf. o ensaio de Neville Morley (2004). Para uma defesa do uso do conceito de Estado para pensar as sociedades da Antiguidade, cf. Finley (1983, p. 1-23). Há um grande debate sobre a pertinência ou não do uso da categoria de classes sociais para entender as sociedades antigas (FINLEY, 1999; STE CROIX, 1998; CARDOSO, 1988, MORLEY, 2004, p. 66-81; ROSE, 2012, p. 1-52) Adoto aqui alguns dos parâmetros propostos por Chris Wickham para a compreensão das relações de classe na Antiguidade Tardia, a saber, que as sociedades do Mediterrâneo antigo e medieval têm como elementos ordenadores e estruturantes o conflito que se dá em torno do excedente socialmente produzido entre grupos sociais produtores diretos e grupos sociais proprietários dos meios de produção e as relações de dominação política associadas a este processo (WICKHAM, 2005, p. 259-302).

${ }^{5}$ Para uma reflexão conceitual sobre a noção de Estado nessas linhas, cf. Haldon (1993), e para um excelente emprego dessa perspectiva, cf. Wickham (2005, p. 56-150).

${ }^{6}$ Meu uso do conceito leva em consideração a problematização da noção feita pelos editores do Journal of Agrarian Change (BERNSTEIN; BYRES, 2001), as críticas de Horden e Purcell (2000, p. 263-287) e as defesas desse conceito feitas por Cam Grey (2011, p. 1-56) e Chris Wickham (2005, p. 383-387; 434441; 519-535).

${ }^{7}$ Uma boa análise dela para períodos anteriores ao século XX pode ser encontrada no ensaio de Santo Mazzarino (1991). Algumas das obras referenciais dessa historiografia no século XX são Max Weber (1983), Rostovtzeff (1926), Ferdinand Lot (1982), Staerman (1980), Perry Anderson (2000), Roger Remondón (1984), Moses Finley (1991) e Geoffrey de Ste Croix (1998).

${ }^{8}$ Foram cruciais para a guinada os trabalhos de Peter Brown (1971) e Henri Marrou (1977). Para os debates historiográficos, cf. Bryan Ward-Perkins (2005, p. 1-10, p. 183), Júlio César Magalhães de Oliveira (OLIVEIRA, 2008), Uiran Gebara da Silva (2009) e Carlos Augusto Ribeiro Machado (2015).

9 Para obras emblemáticas dessa predominância, cf. Cameron (1993) e Bowersock et al. (1999).

${ }^{10}$ Para os representantes mais recentes dessa perspectiva, cf. Ste. Croix (1954), Wallace-Hadrill (1989), Marcone (1993), Whittaker (1993, 1995) e Giliberti (1999, p. 123-129).

${ }^{11}$ Para uma crítica mais detalhada, cf. Krause (1987), Grey (2011) e Silva (2015). 
${ }^{12}$ A obra que melhor representa o consenso é o artigo de A. H. M. Jones (1958), contudo, ela pode ser encontrada já em Saumagne (1937) e a sua presença era ubíqua, cf. Anderson (2000), Finley (1999), Shtaerman e Trofimova (1975), Ste. Croix (1998), ainda sendo muito forte no Brasil: Frighetto (2002, p. 88-114), Machado (2002) e Bastos (2010).

${ }^{13}$ Para descrições mais detalhadas, cf. Giliberti (1999, p. 1-20) e Clausing (1925, p. 31-235).

${ }^{14}$ Essa crítica, aliás, já estava presente em A Economia Antiga (FINLEY, 1999). Cf. o estudo de Kyle Harper para uma extensa apresentação da tese da permanência da escravidão no Império tardio (HARPER, 2011).

${ }^{15}$ NVal 31.1 Quum pure et fideliter observari debeant, quae caventur in legibus, latam dudum de colonis originariis fucum pati quorundam maligna mente cognovimus. Nam quum is, a quo discessit obnoxius, triginta annorum repellatur obiectu, eundo per hos atque alios designatum tempus assumit; ita contingit, ut, quum illi pereat, a quo fugit, nec huic, ad quem venit, possit acquiri, mansionum permutatione desinat esse quod natus est libertatem, quam nascendo non habuit, fugae sibi assiduitate defendens. Nulli umquam, nisi colono fugitivo, culpa sua praemium fuit: ea causa incipit melior effici, qua poenam meretur. (MOMMSEN; MEYER; SIRMOND, 1954. Tradução nossa, grifo nosso). ${ }^{16}$ Cf. particularmente Jones (1958) e, para a versão mais forte, Mirkovic (1997). ${ }^{17}$ Do ponto de vista formal, a diferença entre as duas traduções reside principalmente na função do quod e a qual verbo libertatem serve como objeto. $\mathrm{Na}$ versão de Pharr, quod é o pronome que introduz a subordinada ao verbo desinat esse e libertatem é objeto do verbo defendens. Na minha proposta, libertatem é objeto de desinat esse e o quod atua como uma conjunção introduzindo uma subordinada causal com subjuntivo [desinat esse]. Um argumento a favor da minha escolha reside no fato de que em todas as ocorrências que pude encontrar da construção "quod natus est" em outros autores latinos anteriores, quod nunca funciona como pronome, mas sempre como conjunção introduzindo a subordinada causal, cf. Gel. 17.1; Tac. Dial. 5.3; Mart. 11, 94; Sen. Ben. 3.30; Sen. Con. 2.5, 10.4; Tert. Anim.19.6-7; Jer. Ep. 54; Aus. Ep. 19.31-34.

${ }^{18}$ Embora as normas que foram feitas nas leis devam ser incondicionalmente e fielmente observadas, reconhecemos que a lei lançada há pouco tempo com referência aos colonos por estatuto de nascimento está sendo pervertida pela mente maligna de alguns homens. Pois, uma vez que uma pessoa de quem um colono obrigado se afasta é derrotada pela prescrição de trinta anos, o período de tempo designado é consumido pelo colono que vai de uma pessoa a outra. E assim acontece que, embora o colono seja perdido pela pessoa de quem ele foge, ainda assim, ele não pode ser adquirido por esse a quem vem. Pela mudança constante de moradia, ele cessa de ser o que era ao nascer, e reivindica para si 
mesmo, pela constante repetição de sua fuga, a liberdade que ele não tinha por estatuto de nascimento (Tradução nossa, grifo nosso).

${ }^{19} \mathrm{O}$ artigo de Jones sobre castas ou estamentos no Império tardio apresenta uma boa descrição dessas leis (JONES, 1974).

${ }^{20} \mathrm{O}$ melhor exemplo é Cod. Jus. 11.52, 1, que afirma que os colonos são servi terrae e diz que são livres. Cf. (CARRIÉ, 1997, p. 93-94; GILIBERTI, 1999, p. 14-15).

${ }^{21}$ Miroslav Mirkovic (1997) talvez seja quem melhor expresse a posição contra a qual me oponho aqui. Um dos poucos estudos disponíveis sobre a noção de libertas, concentrando-se no seu uso entre a República e o período inicial do Império, é o de Wirszubiski (1950). Cf. a distinção entre liberty e libertas feita por Arnaldo Momigliano em sua resenha desse livro (1951).

${ }^{22}$ As instituições como a que protegia limitadamente o escravo da violência física, o pecúlio, ou a manumissão, todas eram enquadradas dentro de uma legislação ligada aos direitos de propriedade (HARPER, 2011, p. 355-363).

${ }^{23}$ Quase universalizada para Peter Garnsey (2004).

${ }^{24}$ Peter Garnsey descreve a conexão íntima entre cidadania romana, direitos discricionários e o acesso à lei, embora ele tenha uma interpretação minimalista do impacto da universalização da cidadania romana no Império tardio (GARNSEY, 2004). Uma visão mais positiva desse impacto aparece nas obras de Jill Harries (1999) e de Denis Kehoe (2007, p. 163-192).

\section{Referências}

ANDERSON, P. Passagens da Antiguidade ao Feudalismo. São Paulo: Brasiliense, 2000.

BASTOS, Mário Jorge da Motta. Escravo, Servo ou Camponês? Relações de Produção e Luta de Classes no Contexto da Transição da Antiguidade à Idade Média (Hispânia Séculos V-VIII). Politéia: História e Sociedade, Bahia, v. 10, n. 1, p. 77-105, 2010.

BENJAMIN, W. Sobre o conceito de história. In: Obras Escolhidas: magia e técnica, arte e política. São Paulo: Brasiliense, 1996. p. 222-232.

BERNSTEIN, H.; BYRES, T. J. From Peasant Studies to Agrarian Change. Journal of Agrarian Change, v. 1, n. 1, p. 1-56, 2001.

BOWDEN, W.; LAVAN, L.; MACHADO, C. Recent Research on the Late Antique Countryside. Leiden: Brill, 2004. 
BOWERSOCK, G. W.; BROWN, P.; GRABAR, O. (Org.). Late Antiquity: A Guide to the Postclassical World. Cambridge: Belknap, 1999.

BROWN, P. The World of Late Antiquity. London: Routledge, 1971.

. The Rise of Western Christendom: Triumph and Diversity, AD 2001000. Oxford: Blackwell, 2003.

CAGNAT, René Louis Victor; SCHMIDT, Johannes. Corpus Inscriptionum Latinarum. v. 8. supl. pt. 1. Berolini: Walter de Gruyter, 1966.

CAMERON, A. The Mediterranean World in Late Antiquity: AD 395-700. London: Routledge, 1993.

CARDOSO, Ciro Flamarion S. Economia e Sociedade Antigas: Conceitos e Debates. Clássica, São Paulo, v. 1, 1988, p. 5-20.

CARRIÉ, J.-M. Esclavage antique et ideólogie moderne dans Ancient Slavery and Modern Ideology. Opus, 1982a, p. 161-170.

. Le "colonat du Bas-Empire”: un Mythe Historiographique? Opus, 1982b, p. 351-371.

. Un roman des origines: les généalogies du "colonat du Bas-Empire". Opus, 1983, p. 205-251.

. Colonato del Basso Impero: la resistenza del mito. In: LO CASCIO, E. (Org.). Terre, proprietari e contadidni dello'impero romano. Roma: La nuova Italia Scientifica, 1997. p. 75-150.

CLAUSING, R. The Roman Colonate. The Theories of its Origins. New York: Columbia University, 1925.

CROKE, Brian. Mommsen's Encounter with the Code. In: HARRIES, Jill; WOOD, Ian N. The Theodosian Code: Studies in the Imperial Law of Late Antiquity. London: Duckworth, 1993, p. 217-40.

DE COULANGES, F. Le colonat romain. In: Recherches sur quelques problèmes d'histoire. Paris: Hachette et cie, 1894. p. 3-186.

DYSON, S. L. The Roman countryside. London: Duckworth, 2003.

FINLEY, M. I. Politics in the Ancient World. Cambridge: Cambridge University Press, 1983.

. Escravidão Antiga e Ideologia Moderna. Rio de Janeiro: Graal, 1991. . Ancient Economy. Berkeley: University of California, 1999.

FRIGHETTO, Renan. Cultura e Poder na Antiguidade Tardia Ocidental. Curitiba: Juruá, 2002. 
Governando Camponeses: Colonato e Mobilidade no Império Romano...

GARNSEY, P. Roman Citizenship and Roman Law in the Late Empire. In: SWAIN, S.; EDWARDS, M. (Org.). Approaching Late Antiquity: The Transformation from Early to Late Empire. Oxford: Oxford University Press, 2004. p. 133-155.

GIARDINA, A. The Transition to Late Antiquity. In: SCHEIDEL, W.; MORRIS, I.; SALLER, R. (Org.). The Cambridge Economic History of the Greco-Roman World. Cambridge: Cambridge University, 2007. p. 741-768.

GILIBERTI, G. Servi della terra: ricerche per una storia del colonat. Torino: G. Chiapelli, 1999.

GOFFART, W. A. Caput and colonate: towards a history of late Roman taxation. Toronto: University of Toronto Press, 1974.

. Salvian of Marseille, De Gubernatione Dei 5.38-45 and the "Colonate" Problem. Antiquité Tardive, Paris, 2008, p. 269-288.

GREY, C. Contextualizing Colonatus: the Origo of the Late Roman Empire. Journal of Roman Studies, Londres, v. 27, nov. 2007, p. 155-175.

. Constructing Communities in the Late Roman Countryside. Cambridge: Cambridge University, 2011.

HALDON, J. F. The State and the Tributary Mode of Production. London: Verso, 1993.

HALL, Lynda Jones. Clyde Pharr, the Women of Vanderbilt and Wyoming Judge: the Story behind the Translation of the Theodosian Code in Mid-Century America. Roman Legal Tradition, Glasgow, UK, v. 8, 2012, p. 1-42.

HARPER, K. Slavery in the Late Roman World: AD 275-425. Cambridge: Cambridge University Press, 2011.

HARRIES, J. Law and Empire in Late Antiquity. Cambridge: Cambridge University, 1999.

HEATHER, P. The Fall of the Roman Empire. A new History of Rome and the barbarians. Oxford: Oxford University, 2006.

HONORÉ, T. Roman Law AD 200-400: From Cosmopolis to Rechtstaat? In: SWAIN, S.; EDWARDS, M. (Org.). Approaching Late Antiquity: The Transformation from Early to Late Empire. Oxford: Oxford University Press, 2004. p. 109-132.

HORDEN, P.; PURCELL, N. The Corrupting Sea: A study of Mediterranean History. Oxford: Blackwell, 2000.

Anos 90, Porto Alegre, v. 24, n. 46, p. 185-210, dez. 2017 
JONES, A. H. M. The Roman Colonate. Past \& Present, Oxford, UK, v. 13, n. 1, p. 1-13, abr. 1958.

. The Caste System in the Later Roman Empire. In: BRUNT, P (Org.). The

Roman Economy: Studies in Ancient Economic and Administrative History. Oxford: Blackwell, 1974. p. 396-418.

. The Later Roman Empire. 284-602. Baltimore: Johns Hopkins, 1992.

JONES, A. H. M.; MARTINDALE, J. R. The Prosopography of the Later Roman Empire: AD 395-527. Cambridge: Cambridge University Press, 1980.

KEHOE, D. P. Law and the Rural Economy in the Roman Empire. Ann Arbor, MI: University of Michigan Press, 2007.

KELLY, C. Rulling the Later Roman Empire. Cambridge: Harvard University Press, 2006.

KRAUSE, J.-U. Spätantike Patronatsformen im Westen des Römischen Reiches. München: C. H. Beck, 1987.

LO CASCIO, E. (Org.). Terre, proprietari e contadini dell' impero romano: dall'affitto agrario al colonato tardoantico. Roma: La Nuova Italia Scientifica, 1997.

LOT, F. O fim do mundo antigo e o princípio da Idade Média. Lisboa: Edições 70, 1982.

MACHADO, Carlos Augusto Ribeiro. Grandes proprietários e colonos no Baixo Império Romano. In: CHEVITARESE, André Leonardo. O Campesinato na História. Rio de Janeiro: Dumará, 2002. p. 245-255.

. A Antiguidade Tardia, a Queda do Império Romano e o Debate Sobre o Fim do Mundo Antigo. Revista de História, São Paulo, n. 173, p. 81-114, 2015. MARCONE, A. Il colonato del Tardo Impero: um mito storiografico? Athenaeum, Londres, v. III-IV, 1985, p. 513-520.

. Il colonato tardoantico nella storiografia moderna: da Fustel de Coulanges ai nostri giorni. Como: Edizioni New Press, 1988.

. Il lavoro nelle campagne. In: SCHIAVONE, A. (Org.). Storia di Roma. v. III. Torino: Guilio Einaudi, 1993, p. 823-843.

MARROU, H. I. Décadence romaine ou antiquité tardive? Paris: Éditions du Seuil, 1977.

MARTINO, F. de. Il colonato fra economia i diritto. In: SCHIAVONE, A. (Org.). Storia di Roma. v. III. Torino: Giulio Einaudi, 1993. p. 789-822. 
Governando Camponeses: Colonato e Mobilidade no Império Romano...

MATTHEWS, J. F. Western aristocracies and imperial court: AD 364-425. Oxford: Oxford University, 1990.

. Laying Down the Law. A Study of the Theodosian Code. New Haven: Yale University, 2000.

MAZZARinO, S. O fim do Mundo Antigo. São Paulo: Martins Fontes, 1991.

MIRKOVI , M. The Later Roman Colonate and Freedom. Philadelphia: Transactions of the American Philosophical Society, 1997.

MOMIGLIANO, A. Review of Wirszubski, Ch. Libertas as a Political Idea at Rome during the Late Republic and Early Principate. Journal of Roman Studies, Londres, v. 41, p. 146-153, 1951.

MOMMSEN, T.; MEYER, P. M.; SIRMOND, J. Theodosiani libri XVI cum Constitutionibus Simmondianis: et leges novellae ad Theodosianum pertinentes; consilio et auctoritate Academiae litterarum regiae borussicae. Berlin: Apvd Weidmannos; Deutsche Akademie der Wissenschaften zu Berlin, 1954.

MORLEY, N. Theories, Models, and Concepts in Ancient History. Londres: Routledge, 2004.

OLIVEIRA, J. C. M. de. O Conceito de Antiguidade Tardia e as Transformações da Cidade Antiga: o Caso da África do Norte. Revista de Estudos Filosóficos e Históricos da Antiguidade, Campinas, v. 13, n. 24, p. 125-137, 2008.

PHARR, C. The Theodosian code and novels, and the Sirmondian constitutions. New York: Lawbrook Exchange, 2001.

REMONDON, R. La crisis del Imperio Romano: de Marco Aurelio a Anastasio. Barcelona: Nueva Clio, 1984.

ROSAFIO, P. Studi sul colonato. Bari: Edipuglia, 2002.

ROSE, Peter W. Class in Archaic Greece. Cambridge: Cambridge University Press, 2012.

ROSTOVTZEFF, M. I. The Social \& Economic History of the Roman Empire. New York: Biblo \& Tannen Publishers, 1926.

SAUMAGNE, C. Du rôle de 1'"origo" et du "census" dans la formation du colonat romain. Byzantion, Bruxelas, v. 12, n. 1/2, p. 487-581, 1937.

SCHEIDEL, W. Slaves of the soil: review article. Journal of Roman Archaeology, Portsmouth, v. 13, p. 727-732, 2000. 
SCOTT, J. C. Weapons of the Weak: Everyday Forms of Peasant Resistance. New Haven: Yale University Press, 1985.

SHTAERMAN, E. M.; TROFIMOVA, M. K. La schiavitù nell'Italia imperiale: I-III secolo. Roma: Editori Riuniti, 1975.

SILVA, U. G. da. Antiguidade tardia como forma da História. Anos 90, Porto Alegre, v. 16, n. 30, 2009, p. 77-108.

- Revoltas Camponesas e a Historiografia do Campesinato Romano Tardo-Antigo. In: BASTOS, M. J. M. et al. (Org.). O Pré-Capitalismo em Perspectiva. Estudos em Homenagem ao Prof. Ciro F. S. Cardoso. Rio de Janeiro: Íthaca Edições, 2015. p. 347-367.

SIRKS, B. The Farmer, the Landlord and the Law in the Fitfth Century. In: MATHISEN, R. W. (Org.). Law Society and Authority in Late Antiquity. Oxford: Oxford University, 2001, p. 256-271.

STAERMAN, E. M. La caída del regimen esclavista. In: ESTEPA, C. (Org.). La transición del esclavismo al feudalismo. Madrid: Akal, 1980. p. 59-107.

STE. CROIX, G. E. M. de. Suffragium: From Vote to Patronage. British Journal of Sociology, Londres, v. 5, n. 1, p. 33-48, 1954.

. The class struggle in the Ancient Greek World. Ithaca: Cornell University, 1998.

WALLACE-HADRILL, A. (Org.). Patronage in Ancient Society. London: Routledge, 1989.

WARD-PERKINS, B. Land, Labor and Settlement. In: CAMERON, A. WARD-PERKINS, B.; WHITBY, M. (Org.). The Cambridge Ancient History. Late Antiquity: Empire and Successors AD 425-600. v. XIV. Cambridge: Cambridge University, 2000. p. 315-345.

The Fall of Rome: and the end of civilization. Oxford: Oxford University, 2005.

WEBER, M. As causas sociais da decadência da cultura antiga. In: COHN, G. (Org.). Weber. São Paulo: Ática, 1983.

WHITTAKER, C. R. Circe's Pigs: From Slavery to Serfdom in the Later Roman World. In: . Land, City and Trade in the Roman Empire. Aldershot: Variorum-Ashgate, 1993. p. V, 89-120. 
Governando Camponeses: Colonato e Mobilidade no Império Romano...

. Landlords and warlords. In: SHIPLEY, G.; RICH, J. (Org.). War and society in the roman world. Londres: Routledge, 1995. p. 277-302.

WICKHAM, C. Framing the Early Middle Ages. Europe and the Mediterranean 400-800. Oxford: Oxford University, 2005.

WILMANNS, Gustav. Corpus Inscriptionum Latinarum. v. 8. pt. 2. Berolini: Walter de Gruyter, 1960.

WIRSZUBSKI, C. Libertas as a Political Idea at Rome During the Late Republic and Early Principate. Cambridge: Cambridge University Press, 1950.

Recebido em: 17/11/2016

Aprovado em: 20/04/2017 